\title{
Development of the Effective Reaction Model for Diamond Deposition Simulation within the Continuous Media Approach
}

\author{
Dmitry V. Leshchev ${ }^{1, *}$ and Yuriy E. Gorbachev ${ }^{2}$ \\ ${ }^{1}$ Center for Advanced Studies, Peter the Great St.Petersburg Polytechnic University, RU- 195251, St.-Petersburg, Russia \\ ${ }^{2}$ CoddanTechnologies LLC, RU-197342, St.-Petersburg, Russia
}

\begin{abstract}
Three models for diamond growth process by the chemical vapor deposition of methane are proposed. They differ in the degree of detail of the surface reaction description. The most complete model contains the reactions of deposition, etching and insertion. Gas-dynamic simulations have been performed for all those models. The species delivery to the substrate and the contribution from different species to the growth process is analysed. It is shown that different surface reaction models lead to different profiles of the species concentrations in the immediate vicinity of the substrate, thus, the experimental data on the growth rate may give information on the growth mechanism.
\end{abstract}

\section{Introduction}

Modeling of the chemical processes, which occur during the chemical vapor deposition (CVD) is a complex problem, since it includes modeling of processes and objects of different scales in time and space. Those processes occur under conditions of rather low pressures (transition zone between continuous and molecular description [1]), are attended by clusterization in the gas phase [2], by complex surface processes [3], by large temperature and pressure gradients, and by strong mutual impact of the surface and gas-phase processes.

The CVD of diamonds is a striking example of such a problem: low pressure (2-20 Torr), multi-component mixture (atomic and molecular hydrogen, hydrocarbons and corresponding radicals), significant temperature gradients (from 300 to $2500^{\circ} \mathrm{K}$ ), large number of complicated volumetric and surface processes (volumetric reactions, deposition, etching, species migration over the surface, etc). As previously shown [1], diamond CVD may be simulated both within the continuous media approaches and within the molecular ones.

In studies [3-5] a series of models of diamond growth within the kinetic Monte Carlo approach has been proposed. Those models give a detailed description of the growth process via island formation. They consist of the following steps: activation and deactivation of the surface sites, deposition, etching and migration of $\mathrm{CH}_{2}$, as well as insertion, etching and deposition of the other species. The main issues in using those models in continuous media simulations (where the growth/etching processes are described in gas-surface-bulk terms) consist in the following: (a) migration of the adsorbed particles can hardly be described, (b) reactions proposed in [3] need interpretation for describing the growth/etching processes in surface-bulk terms, (c) some of the reactions from [3] lead to variation of the number of surface sites, that cannot be described within the continuous media approach.

\section{Problem statement}

In [6] the conditions which lead to a high growth rate of diamond (up to $11 \mu \mathrm{m} / \mathrm{h}$ ) and dependence of the growth rate on the distance from the substrate to an atomic hydrogen generation zone have been ascertained. Simulation of corresponding growth process within a simple model (only adsorption reactions were considered) have shown [1] that the dependence of the growth rate from the distance of the substrate from the generation (hot) zone correlates with the $\mathrm{CH}_{2}$ radical concentration, but not with the $\mathrm{CH}_{3}$. That contradicts the generally accepted concept of diamond growth from the methane [3, 7]. Therefore, chemical models, both for gas phase and surface reactions, need revision and thorough consideration. Here we focus only on the impact of the surface reaction sets. Impact of the gas-phase reaction models will be studied elsewhere.

The paper is organized as follows. The next section contains description of three sets of surface reactions modeling the diamond growth: (1) direct deposition of all radicals, (2) deposition of $\mathrm{CH}_{3}$ on the activated sites (dangling bonds) formed during the atomic hydrogen abstraction in recombination reactions (breaking of the $\mathrm{H}-\mathrm{C}$ bond) or in etching processes (breaking of the $\mathrm{C}-\mathrm{C}$ bond), while for other $\mathrm{C}$-containing gas species insertion into the bulk (into the $\mathrm{C}-\mathrm{C}$ bond or the $\mathrm{C}-\mathrm{H}$ bond) is assumed. For comparison: (3) a model from [3] was adapted for the continuous media model. The last section is devoted to the discussion of obtained results and further work. 


\subsection{Model description}

Considered here problem statement is taken as in [8-10]. Axisymmetric calculation domain, corresponding dimensions and boundary conditions are presented in Fig. 1. Conditions at the inlet are as follows: mixture $\mathrm{H}_{2}$ $(1500 \mathrm{sccm})+\mathrm{CH}_{4}(1 \%)$, pressure 20 Torr. An 11-component mixture is considered: $\mathrm{H}_{2}, \mathrm{H}, \mathrm{CH}_{4}, \mathrm{CH}_{3}$, $\mathrm{CH}_{2},{ }^{1} \mathrm{CH}_{2}$ (singlet state), $\mathrm{CH}, \mathrm{C}, \mathrm{C}_{2} \mathrm{H}_{2}, \mathrm{C}_{3}, \mathrm{C}_{2} \mathrm{H}$, and the same set of the volumetric reactions as in $[1,10]$ is used. Surface reactions are presented in Tab.1, while volumetric reactions are repeated in Tab. 2 . Three sets of surface reactions are presented in the next section.

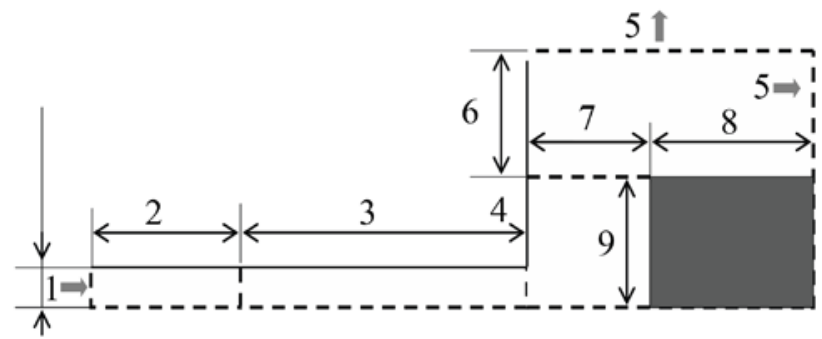

Figure 1. Computation domain with boundary conditions: 1 inlet, $1.5 \mathrm{~mm}, 300 \mathrm{~K}$, flow rates of $\mathrm{H}_{2}$ and $\mathrm{CH}_{4}$ are $1500 \mathrm{sccm}$ and $15 \mathrm{sccm}$, respectively; 2 - cold, $10 \mathrm{~mm}, 300 \mathrm{~K}, 3$ - hot, tungsten, $2400 \mathrm{~K} ; 4$ - hot, $2100 \mathrm{~K} ; 5$ - outlet, $1200 \mathrm{~K} ; 6$ $24 \mathrm{~mm}, 1200 \mathrm{~K} ; 7-10 \mathrm{~mm} ; 8-18 \mathrm{~mm}, 1200 \mathrm{~K} ; 9$ substrate, $8 \mathrm{~mm}, 1200 \mathrm{~K}$; the axis of symmetry is at the bottom of the figure.

Table 1. Probabilities of the surface reactions on different walls $[1,10]$

\begin{tabular}{|c|c|c|}
\hline Reaction & Probability & $\begin{array}{c}\text { Reaction type, } \\
\text { Wall }\end{array}$ \\
\hline $\mathrm{H}_{2} \rightarrow 2 \mathrm{H}$ & 0.04 & $\begin{array}{c}\text { Dissociation, } \\
\text { tungsten }\end{array}$ \\
\cline { 2 - 3 } & 0.025 & Dissociation, hot \\
\hline \multirow{2}{*}{$\mathrm{H} \rightarrow{ }^{1 / 2 \mathrm{H}_{2}}$} & 1 & $\begin{array}{c}\text { Recombination, } \\
\text { cold }\end{array}$ \\
\cline { 2 - 3 } & 0.75 & $\begin{array}{c}\text { Recombination, } \\
\text { substrate }\end{array}$ \\
\cline { 2 - 3 } & 0.24 & $\begin{array}{c}\text { Recombination, } \\
\text { tungsten }\end{array}$ \\
\cline { 2 - 3 } & 0.8 & $\begin{array}{c}\text { Recombination, } \\
\text { hot }\end{array}$ \\
\hline
\end{tabular}

Table 2. List of volumetric reactions and corresponding rate constant parameters $[1,10]$ (Arrhenius form, $\mathrm{AT}^{\mathrm{b}} \exp (-\mathrm{Ea} / \mathrm{T}), \mathrm{A}$ is in $\left.\mathrm{m}^{3} / \mathrm{kmol} \cdot \mathrm{s}\right)$.

\begin{tabular}{|c|c|c|c|c|}
\hline & Reaction & A & b & Ea,K \\
\hline R1 & $\mathrm{H}^{+} \mathrm{CH}_{4} \rightarrow \mathrm{CH}_{3}+\mathrm{H}_{2}$ & $6.6 \mathrm{E}+05$ & 1.62 & 5453 \\
\hline R2 & $\mathrm{CH}_{3}+\mathrm{H}_{2} \rightarrow \mathrm{H}+\mathrm{CH}_{4}$ & 31940 & 1.62 & 5175 \\
\hline R3 & $\mathrm{H}+\mathrm{H}+\mathrm{H}_{2} \rightarrow \mathrm{H}_{2}+\mathrm{H}_{2}$ & $9.0 \mathrm{E}+10$ & -0.6 & 0 \\
\hline R4 & $\mathrm{H}_{2}+\mathrm{H}_{2} \rightarrow \mathrm{H}+\mathrm{H}+\mathrm{H}_{2}$ & $2.87 \mathrm{E}+14$ & -0.6 & 51851 \\
\hline R5 & $\mathrm{CH}_{2}+\mathrm{H}_{2} \rightarrow \mathrm{H}+\mathrm{CH}_{3}$ & $5.0 \mathrm{E}+02$ & 2 & 3637 \\
\hline R6 & $\mathrm{H}+\mathrm{CH}_{3} \rightarrow \mathrm{CH}_{2}+\mathrm{H}_{2}$ & 2571 & 2 & 6571 \\
\hline R7 & ${ }^{1} \mathrm{CH}_{2}+\mathrm{H}_{2} \rightarrow \mathrm{H}+\mathrm{CH}_{3}$ & $7.0 \mathrm{E}+10$ & 0 & 0 \\
\hline R8 & $\mathrm{H}^{+} \mathrm{CH}_{3} \rightarrow{ }^{1} \mathrm{CH}+\mathrm{H}_{2}$ & $1.75 \mathrm{E}+11$ & 0 & 7076 \\
\hline
\end{tabular}

\begin{tabular}{|c|c|c|c|c|}
\hline R9 & $\mathrm{CH}+\mathrm{H}_{2} \rightarrow \mathrm{H}+\mathrm{CH}_{2}$ & $1.1 \mathrm{E}+11$ & 0 & 1564 \\
\hline R10 & $\mathrm{H}+\mathrm{CH}_{2} \rightarrow \mathrm{CH}+\mathrm{H}_{2}$ & $1.88 \mathrm{E}+11$ & 0 & 219 \\
\hline R11 & $\mathrm{H}+{ }^{1} \mathrm{CH}_{2} \rightarrow \mathrm{CH}+\mathrm{H}_{2}$ & $3.0 \mathrm{E}+10$ & 0 & 0 \\
\hline R12 & $\mathrm{CH}+\mathrm{H}_{2} \rightarrow \mathrm{H}+{ }^{1} \mathrm{CH}_{2}$ & $8.41 \mathrm{E}+09$ & 0 & 5487 \\
\hline R13 & $\mathrm{H}+\mathrm{CH} \rightarrow \mathrm{H}_{2}+\mathrm{C}$ & $1.6 \mathrm{E}+11$ & 0 & 0 \\
\hline R14 & $\mathrm{H}_{2}+\mathrm{C} \rightarrow \mathrm{H}+\mathrm{CH}$ & $5.41 \mathrm{E}+11$ & 0 & 11716 \\
\hline R15 & $\mathrm{C}+\mathrm{CH}_{3} \rightarrow \mathrm{C}_{2} \mathrm{H}_{2}+\mathrm{H}$ & $5.0 \mathrm{E}+10$ & 0 & 0 \\
\hline R16 & $\mathrm{C}_{2} \mathrm{H}_{2}+\mathrm{H} \rightarrow \mathrm{C}+\mathrm{CH}_{3}$ & $1.07 \mathrm{E}+12$ & 0 & 50110 \\
\hline R17 & $\mathrm{CH}+\mathrm{CH}_{2} \rightarrow \mathrm{C}_{2} \mathrm{H}_{2}+\mathrm{H}$ & $4.0 \mathrm{E}+10$ & 0 & 0 \\
\hline R18 & $\mathrm{C}_{2} \mathrm{H}_{2}+\mathrm{H} \rightarrow \mathrm{CH}+\mathrm{CH}_{2}$ & $1.42 \mathrm{E}+13$ & 0 & 64726 \\
\hline R19 & $\mathrm{CH}_{2}+\mathrm{CH}_{2} \rightarrow \mathrm{C}_{2} \mathrm{H}_{2}+\mathrm{H}_{2}$ & $1.6 \mathrm{E}+12$ & 0 & 6008 \\
\hline R20 & $\mathrm{C}_{2} \mathrm{H}_{2}+\mathrm{H}_{2} \rightarrow \mathrm{CH}_{2}+\mathrm{CH}_{2}$ & $3.33 \mathrm{E}+14$ & 0 & 72126 \\
\hline R21 & $\mathrm{C}+\mathrm{C}_{2} \mathrm{H}_{2} \rightarrow \mathrm{C}_{3}+\mathrm{H}_{2}$ & $1.6 \mathrm{E}+11$ & -0.12 & 0 \\
\hline R22 & $\mathrm{C}_{3}+\mathrm{H}_{2} \rightarrow \mathrm{C}+\mathrm{C}_{2} \mathrm{H}_{2}$ & $1.19 \mathrm{E}+11$ & -0.12 & 13223 \\
\hline R23 & $\mathrm{C}+\mathrm{CH}_{2} \rightarrow \mathrm{C}_{2} \mathrm{H}+\mathrm{H}$ & $5.0 \mathrm{E}+10$ & 0 & 0 \\
\hline R24 & $\mathrm{C}_{2} \mathrm{H}+\mathrm{H} \rightarrow \mathrm{C}+\mathrm{CH}_{2}$ & $2.84 \mathrm{E}+11$ & 0 & 38627 \\
\hline R25 & $\mathrm{C}_{2} \mathrm{H}+\mathrm{H}_{2} \rightarrow \mathrm{H}+\mathrm{C}_{2} \mathrm{H}_{2}$ & $5.7 \mathrm{E}+07$ & 0.9 & 1003 \\
\hline R26 & $\mathrm{H}+\mathrm{C}_{2} \mathrm{H}_{2} \rightarrow \mathrm{C}_{2} \mathrm{H}+\mathrm{H}_{2}$ & $1.08 \mathrm{E}+09$ & 0.9 & 15386 \\
\hline
\end{tabular}

\subsection{Direct deposition}

Within the first model, diamond growth occurs due to the sticking of radicals containing carbon atoms to the surface (see table 3, where (b) indicates the bulk; index 1 in ${ }^{1} \mathrm{CH}_{2}$ corresponds to the singlet state of a methylene). The hydrogen penetrating into the bulk is not considered. It is assumed that it can leave the bulk after recombination. Impact of that hydrogen on the gas flow is negligible due its small amount.

Such simplified approach does not allow a description of mutual impact of different adsorbing components on each other, thus, the models containing at least the processes of formation and depletion of the activated surface sites, and of deposition/abstraction of some components are required. Therefore, another two models with different levels of specification of gassurface-bulk interactions are proposed and analyzed

Table 3. Probabilities of the surface reactions on the wafer, model 1.

\begin{tabular}{|c|c|c|c|}
\hline & Reaction & Probability & RT \\
\hline 1.1 & $\mathrm{C} \rightarrow \mathrm{C}(\mathrm{b})$ & 0.05 & $\mathrm{D}$ \\
\hline 1.2 & $\mathrm{C}_{3} \rightarrow \mathrm{C}_{3}(\mathrm{~b})$ & 0.05 & $\mathrm{D}$ \\
\hline 1.3 & $\mathrm{CH}_{3} \rightarrow \mathrm{CH}_{3}(\mathrm{~b})$ & 0.005 & $\mathrm{D}$ \\
\hline 1.4 & $\mathrm{CH}_{2} \rightarrow \mathrm{CH}_{2}(\mathrm{~b})$ & 0.05 & $\mathrm{D}$ \\
\hline 1.5 & ${ }^{1} \mathrm{CH}_{2} \rightarrow{ }^{1} \mathrm{CH}_{2}(\mathrm{~b})$ & 0.05 & $\mathrm{D}$ \\
\hline 1.6 & $\mathrm{CH} \rightarrow \mathrm{CH}(\mathrm{b})$ & 0.05 & $\mathrm{D}$ \\
\hline 1.7 & $\mathrm{C}_{2} \mathrm{H} \rightarrow \mathrm{C}_{2} \mathrm{H}(\mathrm{b})$ & 0.05 & $\mathrm{D}$ \\
\hline
\end{tabular}

\section{3. "Linear growth" model}

The model is described by the surface reactions, listed in Table 4. Activation energies for reactions of recombination of hydrogen and methane, $2.1-2.4$, have 
been calculated by the quantum-chemical method (for simplicity they are taken the same for all these reactions), while preexponential coefficients are taken from the data for similar reactions from [3]. The same concerns the etching of $\mathrm{CH}_{3}$, reaction 2.5. The main idea of this approach consists in employment of the two-step model (Matsuda model [11]) extended by the insertion process: (1) activated surface sites (dangling bonds) formation due to both recombination reactions and etching by atomic hydrogen or methyl (reactions 2.1, 2.3, 2.4, 2.12), (2) sticking of the methyl to the activated sites (reaction 2.13), (3) growth by the direct insertion into the bulk (reactions 2.6-2.11). That stuck methyl can further form the activated site after aforementioned recombination act. Other gas species can directly insert into the bulk via inserting into $\mathrm{C}-\mathrm{C}$ or $\mathrm{C}-\mathrm{H}$ bond (without changing the number of surface sites). Hydrogen penetrating the bulk is not considered as previously. All insertion reactions lead to the diamond growth. The main differences of the proposed model from the Matsuda's consist in consideration of the etching, which can lead to the decrease of the growth rate, and in the insertion, which can lead to its increase.
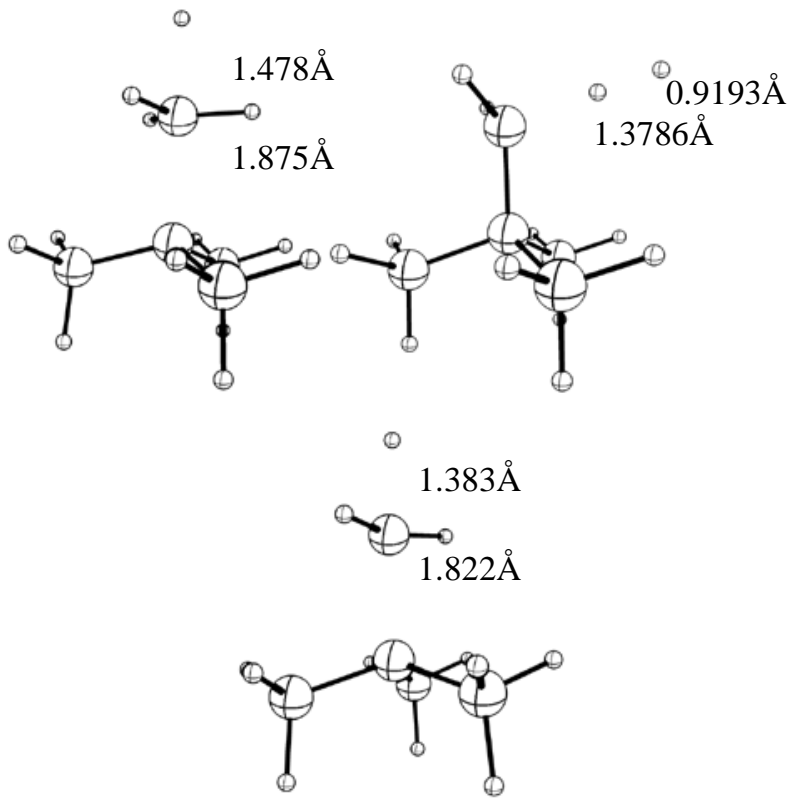

Figure 2. Transition states for the reaction of $\mathrm{CH}_{3}$ etching by atomic hydrogen, and for a hydrogen recombination, and $\mathrm{CH}_{2}$ etching in the similar way.

Due to the high concentration of the atomic hydrogen in the gas phase, formation of the surface site by a surface carbon atom with two dangling bonds is very unlikely. Thus, we can consider only C(s) site, which is a carbon radical on the surface with one dangling bond (activated site), $\mathrm{CH}(\mathrm{s})$ is the corresponding deactivated site (passivated by hydrogen); $\mathrm{CH}_{3}$ (s) is the site with a methyl group on the surface, i.e. is an activated site which is passivated by methyl: carbon from a methyl group is bonded with a carbon of an activated site (see Fig. 3, top).

Etching is described by the reaction 2.5 . Corresponding activation energy, $27.5 \mathrm{kcal} / \mathrm{mol}$, is calculated by quantum-mechanic calculations via DFT b3lyp method, the basis set is 6-31g(p,d). Geometry of the transition state is presented in Fig. 2. In contrast to [3], where the etching of $\mathrm{CH}_{2}$ was considered: $\mathrm{H}+\mathrm{CH}_{2} \mathrm{C}(\mathrm{s}) \rightarrow \mathrm{CH}_{3}+\mathrm{C}(\mathrm{s})$, the proposed reaction has much lower activation energy, that leads to a higher etching rate, but still it is only $0.05 \%$ of the activation rate (reaction 2.3) and $0.02 \%$ of the $\mathrm{CH}_{3}$ deposition rate (reaction 2.13).

Table 4. Probabilities of the surface reactions on the wafer, model 2, reaction type (RT): A — site activation, D - site deactivation, $\mathrm{E}$ - etching, G - growth, I - insertion.

\begin{tabular}{|c|c|c|c|}
\hline & Reaction & Probability/A,n,Ea & RT \\
\hline 2.1 & $\mathrm{H}+\mathrm{CH}(\mathrm{s}) \rightarrow \mathrm{H}_{2}+\mathrm{C}(\mathrm{s})$ & $1.9 \mathrm{E}+9,0.5,3973$ & A \\
\hline 2.1 & $\mathrm{H}_{2}+\mathrm{C}(\mathrm{s}) \rightarrow \mathrm{H}+\mathrm{CH}(\mathrm{s})$ & $1.9 \mathrm{E}+8,0.5,5331$ & $\mathrm{D}$ \\
\hline 2.2 & $\mathrm{H}+\mathrm{C}(\mathrm{s}) \rightarrow \mathrm{CH}(\mathrm{s})$ & $5.8 \mathrm{E}+8,0.5,0$ & $\mathrm{D}$ \\
\hline 2.3 & $\mathrm{H}^{\prime} \mathrm{CH}_{3}(\mathrm{~s}) \rightarrow \mathrm{H}_{2}+\mathrm{C}(\mathrm{s})$ & $1.9 \mathrm{E}+9,0.5,3973$ & A \\
\hline 2.4 & $\mathrm{CH}_{3}+\mathrm{CH}_{3}(\mathrm{~s}) \rightarrow \mathrm{CH}_{4}+\mathrm{C}(\mathrm{s})$ & $1.9 \mathrm{E}+9,0.5,3973$ & A \\
\hline 2.5 & $\mathrm{H}^{+} \mathrm{CH}_{3}(\mathrm{~s})+\mathrm{C}(\mathrm{b}) \rightarrow \mathrm{CH}_{4}+\mathrm{C}(\mathrm{s})$ & $1 \mathrm{E}+9,0.5,13849$ & E \\
\hline 2.6 & $\mathrm{CH}_{2} \rightarrow \mathrm{H}_{2}+\mathrm{C}(\mathrm{b})$ & 0.05 & $\mathrm{I}$ \\
\hline 2.7 & ${ }^{1} \mathrm{CH}_{2} \rightarrow \mathrm{H}_{2}+\mathrm{C}(\mathrm{b})$ & 0.05 & $\mathrm{I}$ \\
\hline 2.8 & $\mathrm{CH} \rightarrow 1 / 2 \mathrm{H}_{2}+\mathrm{C}(\mathrm{b})$ & 0.05 & $\mathrm{I}$ \\
\hline 2.9 & $\mathrm{C} \rightarrow \mathrm{C}(\mathrm{b})$ & 0.05 & $\mathrm{I}$ \\
\hline 2.10 & $\mathrm{C} 3 \rightarrow 3 \mathrm{C}(\mathrm{b})$ & 0.05 & $\mathrm{I}$ \\
\hline 2.11 & $\mathrm{C}_{2} \mathrm{H} \rightarrow 1 / 2 \mathrm{H}_{2}+2 \mathrm{C}(\mathrm{b})$ & 0.05 & $\mathrm{I}$ \\
\hline 2.12 & $\mathrm{CH}_{3}+\mathrm{CH}(\mathrm{s}) \rightarrow \mathrm{CH}{ }_{4}+\mathrm{C}(\mathrm{s})$ & $1.9 \mathrm{E}+9,0.5,3973$ & A \\
\hline 2.12 & $\mathrm{CH}_{4}+\mathrm{C}(\mathrm{s}) \rightarrow \mathrm{CH}_{3}+\mathrm{CH}(\mathrm{s})$ & $1.9 \mathrm{E}+8,0.5,5331$ & $\mathrm{D}$ \\
\hline 2.13 & $\mathrm{CH}_{3}+\mathrm{C}(\mathrm{s}) \rightarrow \mathrm{CH}_{3}(\mathrm{~s})+\mathrm{C}(\mathrm{b})$ & $5.8 \mathrm{E}+8,0.5,0$ & $\mathrm{G}$ \\
\hline
\end{tabular}

\subsection{Adapted model}

To compare the simulation results, based on our models, with those obtained from the model proposed in [3], the last was adapted for application within the continuous media approach. The main issue of such adaptation consists in absence in that model of the reactions, that can be interpreted as deposition. Deposition in [3] may occur only after migration. Another issue consists in that some of the surface sites (such as $-\mathrm{CH}_{2}-\mathrm{C}_{\mathrm{d}}-\mathrm{C}_{\mathrm{d}} \mathrm{H}$, where $\mathrm{C}_{\mathrm{d}}$ are the atoms from the diamond bulk) do not participate in the growth process, therefore, they can passivate the surface and stop the growth process. Etching reactions proposed in [3] seems to be artificial, since, as discussed in the previous section, other etching reactions are more likely. The fact is that only the methyl group can be easily etched. Others need braking of two $\mathrm{C}-\mathrm{C}$ bonds while only one $\mathrm{C}-\mathrm{H}$ bond is formed. Thus, the etching of those species can be neglected. Though the $\mathrm{CH}_{2}$ group on the surface is a key element of the growth process for the model from [3], its evolution after adsorption is not clearly described. Etching only for the mobile surface species (that can migrate along the surface) $\mathrm{CH}_{\mathrm{x}}, \mathrm{x}=1-3$, is considered, therefore we excluded the etching from our continuous media model. For the reaction of methyl adsorption (reaction 3.7) the data from [3], Tab. II, Eq. (7) is used. 


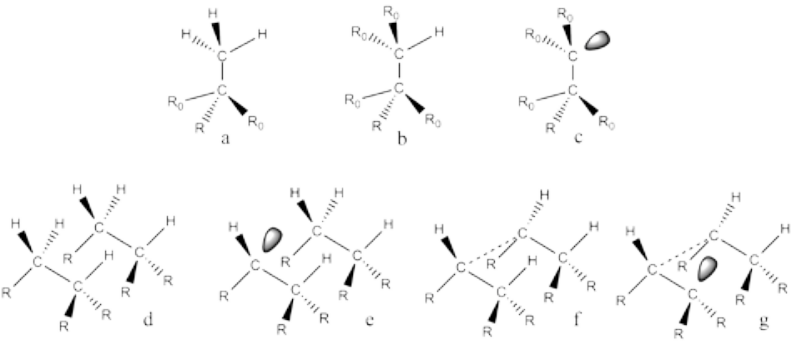

Figure 3. Sites from models 2 and 3: a-c - evolution of sites in model 2: $\mathrm{CH}_{3}, \mathrm{CH}, \mathrm{C}$; d-g - evolution of sites from $\mathrm{CH}_{3}$ to $\mathrm{C}$ in model 3 , $\mathrm{R}$ denotes the carbon atom inserted into the diamond, $\mathrm{R}_{0}-\mathrm{R}$, C-containing radical or $\mathrm{H}$.

The set of considered surface sites is presented in Fig. 3 (bottom). Parameters of the reaction probabilities, presented in Table 5, are taken from [3-5], parameters of deposition probabilities for species which are not considered there, are chosen by analogy (A and Ea are in $\mathrm{m}^{3} / \mathrm{kmol} \cdot \mathrm{s}$ and in $\mathrm{K}$, respectively, the site surface density is $1.3 \mathrm{E}-8 \mathrm{kmol} / \mathrm{m}^{2}$ ). As the insertion reaction parameters, we set the parameters of reaction from [3] Tab. II, Eq. (7).

Table 5. Probabilities of the surface reactions on the wafer, model 3. Notations are as in table 4.

\begin{tabular}{|c|c|c|c|}
\hline & Reaction & Probability/A,n,Ea & RT \\
\hline 3.1 & $\mathrm{H}+\mathrm{CH}_{3}(\mathrm{~s}) \rightarrow \mathrm{H}_{2}+\mathrm{CH}_{2}(\mathrm{~s})$ & $1.9 \mathrm{E}+9,0.5,3430$ & A \\
\hline $3.1^{\prime}$ & $\mathrm{H}_{2}+\mathrm{CH}_{2}(\mathrm{~s}) \rightarrow \mathrm{H}+\mathrm{CH}_{3}(\mathrm{~s})$ & $1.9 \mathrm{E}+8,0.5,7850$ & $\mathrm{D}$ \\
\hline 3.2 & $\mathrm{H}+\mathrm{CH}_{2}(\mathrm{~s}) \rightarrow \mathrm{H}_{2}+\mathrm{CH}(\mathrm{s})$ & $1.9 \mathrm{E}+9,0.5,3430$ & A \\
\hline $3.2^{\prime}$ & $\mathrm{H}_{2}+\mathrm{CH}(\mathrm{s}) \rightarrow \mathrm{H}+\mathrm{CH}_{2}(\mathrm{~s})$ & $1.9 \mathrm{E}+8,0.5,7850$ & $\mathrm{D}$ \\
\hline 3.3 & $\mathrm{H}+\mathrm{CH}(\mathrm{s}) \rightarrow \mathrm{H}_{2}+\mathrm{C}(\mathrm{s})$ & $1.9 \mathrm{E}+9,0.5,3430$ & A \\
\hline $3.3^{\prime}$ & $\mathrm{H}_{2}+\mathrm{C}(\mathrm{s}) \rightarrow \mathrm{H}+\mathrm{CH}(\mathrm{s})$ & $1.9 \mathrm{E}+8,0.5,7850$ & $\mathrm{D}$ \\
\hline 3.4 & $\mathrm{H}+\mathrm{CH}_{2}(\mathrm{~s}) \rightarrow \mathrm{CH}_{3}(\mathrm{~s})$ & $5.8 \mathrm{E}+8,0.5$ & $\mathrm{D}$ \\
\hline 3.5 & $\mathrm{H}+\mathrm{CH}(\mathrm{s}) \rightarrow \mathrm{CH}_{2}(\mathrm{~s})$ & $5.8 \mathrm{E}+8,0.5$ & $\mathrm{D}$ \\
\hline 3.6 & $\mathrm{H}+\mathrm{C}(\mathrm{s}) \rightarrow \mathrm{CH}(\mathrm{s})$ & $5.8 \mathrm{E}+8,0.5$ & $\mathrm{D}$ \\
\hline 3.7 & $\mathrm{CH}_{3}+\mathrm{C}(\mathrm{s}) \rightarrow \mathrm{C}(\mathrm{b})+\mathrm{CH}_{3}(\mathrm{~s})$ & 0.075 & G \\
\hline 3.8 & $\mathrm{CH}_{2}+\mathrm{CH}(\mathrm{s}) \rightarrow \mathrm{C}(\mathrm{b})+\mathrm{CH}_{3}(\mathrm{~s})$ & 0.12 & $\mathrm{G}$ \\
\hline 3.9 & $\begin{array}{c}{ }^{1} \mathrm{CH}_{2}+\mathrm{CH}(\mathrm{s}) \rightarrow \mathrm{C}(\mathrm{b})+\mathrm{CH}_{3}(\mathrm{~s} \\
)\end{array}$ & 0.12 & G \\
\hline 3.10 & $\mathrm{CH}+\mathrm{CH}(\mathrm{s}) \rightarrow \mathrm{C}(\mathrm{b})+\mathrm{CH}_{2}(\mathrm{~s})$ & 0.175 & $\mathrm{G}$ \\
\hline 3.11 & $\mathrm{CH}_{2} \rightarrow \mathrm{H}_{2}+\mathrm{C}(\mathrm{b})$ & 0.12 & $\mathrm{I}$ \\
\hline 3.12 & ${ }^{1} \mathrm{CH}_{2} \rightarrow \mathrm{H}_{2}+\mathrm{C}(\mathrm{b})$ & 0.12 & I \\
\hline 3.13 & $\mathrm{CH} \rightarrow 1 / 2 \mathrm{H}_{2}+\mathrm{C}(\mathrm{b})$ & 0.175 & I \\
\hline 3.14 & $\mathrm{C} \rightarrow \mathrm{C}(\mathrm{b})$ & 0.3 & I \\
\hline 3.15 & $\mathrm{C}_{3} \rightarrow 3 \mathrm{C}(\mathrm{b})$ & 0.3 & I \\
\hline 3.16 & $\mathrm{C}_{2} \mathrm{H} \rightarrow 1 / 2 \mathrm{H}_{2}+2 \mathrm{C}(\mathrm{b})$ & 0.3 & I \\
\hline
\end{tabular}

\section{Results and discussion}

All considered models significantly overestimate the experimental data for the growth rate $(11 \mu \mathrm{m} / \mathrm{h}[6])$, therefore, the presented rates are normalized to their mean values along the substrate. Figs. 4 and 5 show that for the direct deposition model (model 1) the growth rate profile is flatter and correlates with the profiles of the carbon-containing species near the substrate. Atomic hydrogen has a characteristic profile with a maximum in the center, deposition rate for the reactions with the activated sites has the similar profile (Fig. 7).
Thus, the experimental data on the growing diamond profiles is welcome, since this data contain the information on the deposition mechanism and even may provide an opportunity to evaluate the parameters of corresponding effective reactions.

Species deposition in model 1 is proportional to their concentrations near the substrate. Provided that the corresponding sticking coefficients are small, those concentrations are slightly depended on the surface reactions, therefore corresponding reaction rates can be considered as the functions of sticking coefficients only, and can be simply estimated if these coefficients are varied. Thus, if the sticking coefficient for $\mathrm{CH}_{3}$ is of the same order as for other radicals (Tab. 3), its contribution increases by 10 times (Fig. 6).

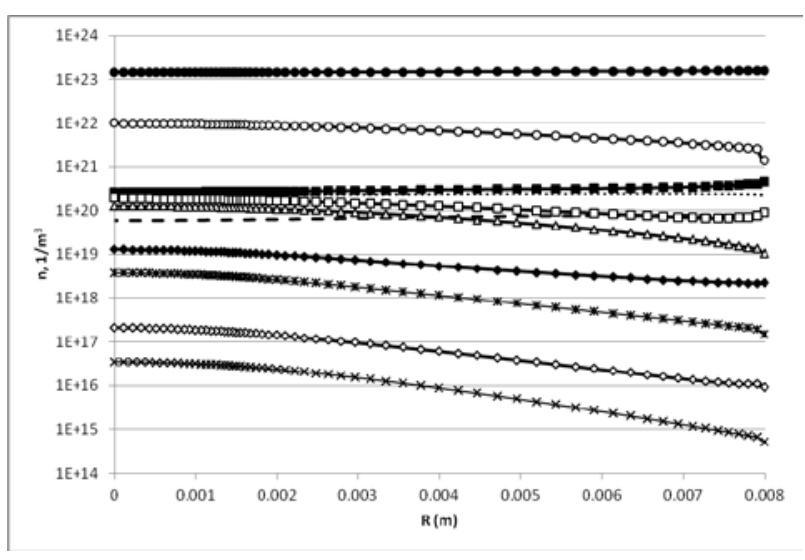

Figure 4. Profiles of the main species number densities along the substrate for model 1, 0 corresponds to the symmetry axis: $\mathrm{H}_{2}$ - solid line, solid circles; $\mathrm{H}$ - solid line, empty circles; $\mathrm{CH}_{4}$ - solid line, solid squares; $\mathrm{CH}_{3}$ - solid line, empty squares; $\mathrm{CH}_{2}$ - solid line, solid diamonds; ${ }^{1} \mathrm{CH}_{2}$ - solid line, empty diamonds; $\mathrm{CH}$ - thin line, asterisks; $\mathrm{C}_{2} \mathrm{H}$ - thin line, crosses; $\mathrm{C}_{2} \mathrm{H}_{2}$ - point line, no markers; $\mathrm{C}$ - solid line, empty triangles; $\mathrm{C}_{3}$ - dotted line, no markers.

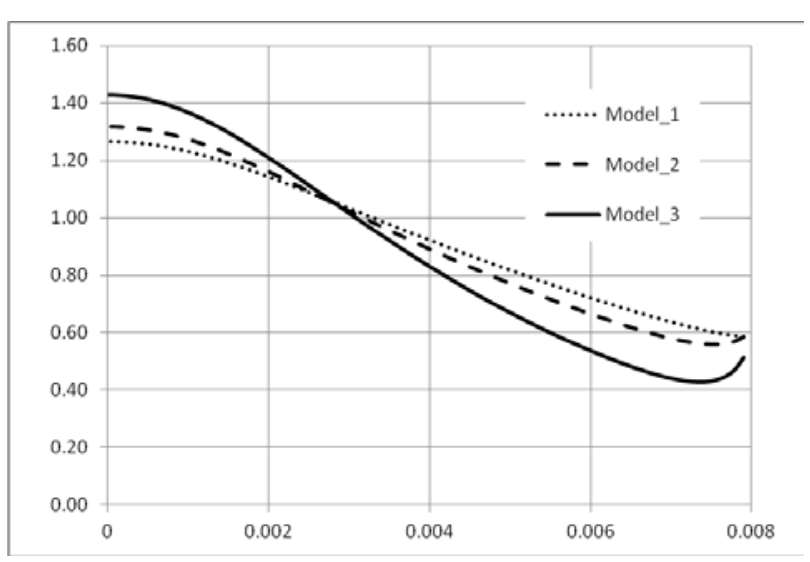

Figure 5. Normalized profiles of the total growth rates: points - model 1, dotted - model 2, solid - model 3. 

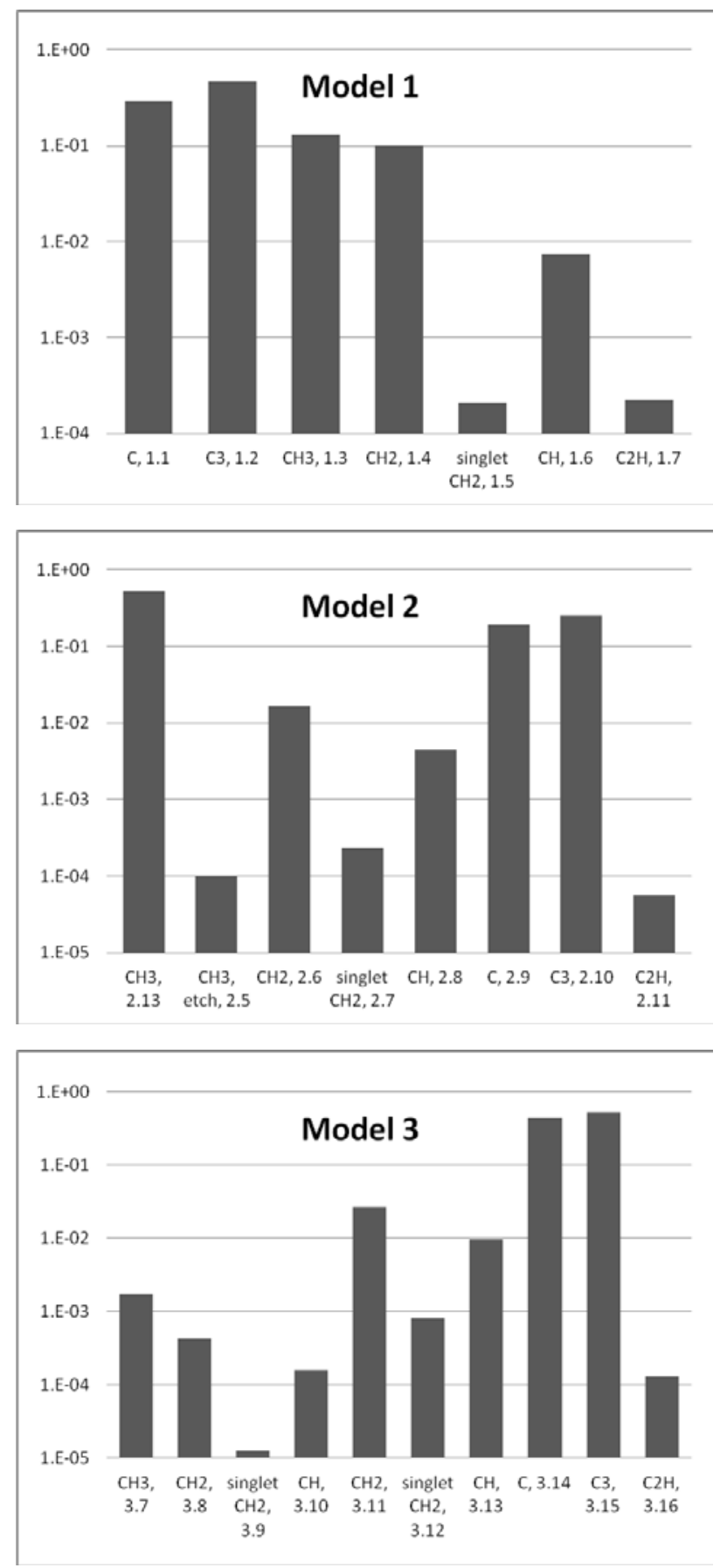

Figure 6. Diagrams of the contribution of different species to the growth rate for three considered models (logarithmic scale). Since contribution of the etching reaction 2.5 has the negative sign, here it is shown with an opposite sign. Under columns corresponding species and reactions are mentioned.

In model 2 the main deposition is provided by reactions $2.13,2.10$ and 2.9, i.e. by methyl deposition and carbon insertion. The surface is covered mostly by the $\mathrm{CH}(\mathrm{s})$ sites, i.e. is passivated by hydrogen, while a minor concentration of $\mathrm{CH}_{3}(\mathrm{~s})$ sites is observed (Fig. 7a). From the values of the corresponding rate constants it follows that this site mainly is converted into the activated site $\mathrm{C}(\mathrm{s})$ by reaction 2.3 , while etching weakly impacts the growth rate.

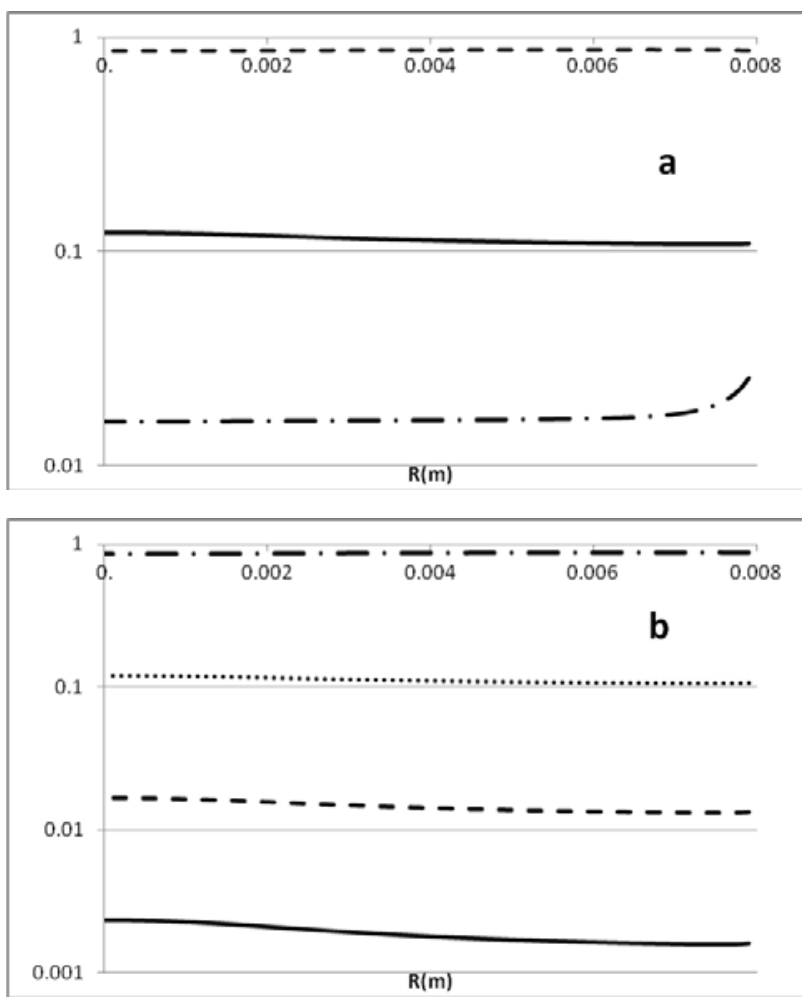

Figure 7. (a) and (b) - site concentration distributions for models 2 and 3, respectively: $\mathrm{C}$ - solid line, $\mathrm{CH}$ - dotted line, $\mathrm{CH}_{2}$ - points line, $\mathrm{CH}_{3}$ - point-dotted line (logarithmic scale), distance from the substrate center is in $\mathrm{m}$.

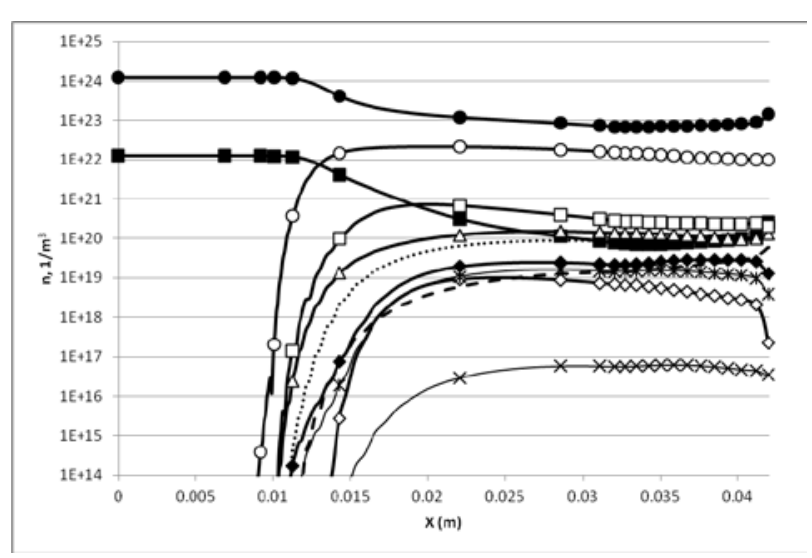

Figure 8. Profiles of number densities of the main species along symmetry axis for model 2 . Notations are the same as in Fig. 4.

In model 3 the main deposition is provided by reactions 3.14 and 3.15, that are only carbon insertion. As in the second model, the surface is mostly covered by deactivated sites $\left(\mathrm{CH}(\mathrm{s})\right.$ and $\mathrm{CH}_{3}(\mathrm{~s})$ in models 2 and 3 , respectively), Fig. $7 \mathrm{~b}$, which can only degrade to the $\mathrm{C}(\mathrm{s})$ sites via $\mathrm{H}$ detachment reactions. Comparison of the simulation results obtained within the second and third models shows that the model proposed in [3] hardly can be used for the growth process description. Within that model, methyl can be adsorbed only at the activated site, which is formed after three successive detachments of hydrogen atoms via reactions of hydrogen recombination. In real situation, those detachments are accompanied by the reverse reactions of atomic 
hydrogen sticking, with rates 10 times higher than that for the detachment. Both those reactions are fast [3], therefore, the site distribution is close to equilibrium, i.e. the ratio of numbers of corresponding sites will be 1:10. As a result, the part of the activated sites is about 0.0016 (see Fig. 7b). Therefore, the methyl deposition rate (Table 5, reaction 3.7) will be very low. So, the attachment of the methyl (or any other gas-phase radical) to each of the intermediate activated sites of this threestep series is more likely. Since those reactions of deactivation are not included in the model, formation of the aforementioned active sites is overestimated in [3] and is questionable for the real surfaces. As is generally accepted [7], $\mathrm{CH}_{3}$ gives the main contribution to the growth process, thus, the model of "linear growth" is more relevant to the experimental data. Further site evolution does not affect the diamond growth rate. Therefore, we can exclude the complex surface transformations from the growth model.

Distributions of number densities of species along the axis are shown in Fig. 8. For all three models they are almost identical, the difference is observed only in the close proximity to the substrate. Both $\mathrm{CH}_{3}$ and $\mathrm{H}$ number densities gradually decrease after exiting the tube: $\mathrm{CH}_{3}$ due to the collisions with $\mathrm{H}$ in reactions $\mathrm{R} 6$ and $\mathrm{R} 8, \mathrm{H}$ due to the collisions with the most of carbon species and volumetric recombination. However, carbon ( $\mathrm{C}$ and $\mathrm{C}_{3}$ ) concentrations rapidly approaches corresponding values for methyl and, thus, their deposition determines the growth rate of the carbon phase on the substrate. A mechanism preventing their insertion into the growing diamond should be considered. For that we would propose to reduce the direct insertion probability and to include the reaction of insertion via surface sites, such as $\mathrm{C}+\mathrm{C}(\mathrm{s}) \rightarrow \mathrm{C}(\mathrm{s})+\mathrm{C}(\mathrm{b})$.

The graphite is more inert to hydrogenation and easier to grow via carbon deposition. The insertion reaction should be left to $\mathrm{CH}_{2}$ and $\mathrm{CH}$ particles that save $\mathrm{sp}^{3}$ hybridization without additional hydrogenation.

In our further work we plan to revise the gas-phase chemistry, since the present set of reactions leads to very high concentration of radicals $\mathrm{CH}_{\mathrm{x}}, \mathrm{x}=0-3$ and $\mathrm{C}_{3}$. Experimental data on growth rates only indirectly indicate the gas-phase chemistry, still, the accumulated data contain the information on correlations with the geometry variation [6] and with the input data [12], which may help in understanding the paths of chemical transformations leading to the growth.

Another step concerns the surface chemistry. In particular, the discrepancy between the experimentally observed high etching rate [3] and low rate in the current model requires the model adjustment. To reduce the contribution from the insertion of radicals $\mathrm{CH}_{\mathrm{x}}, \mathrm{x}=0-2$, the reaction of type of 2.4 with those radicals should be taken into account. This will lead to increasing of the methyl concentration and decreasing of concentrations of other carbon-containing radicals.

This work was partially supported by the Russian Foundation for Basic Research (project № 19-08-00533).

\section{References}

1. Yu.E. Gorbachev, D.V. Leshchev, M.Yu. Plotnikov, A.K.Rebrov, I.B.Yudin, J. Phys.: Conf. Series, (2019) (accepted for publication).

2. G.A. Lukyanov, D.V. Leshchev, S.V. Kozyrev, A.N. Volkov, N.Y. Bykov, O.I. Vakulova, Y. Khang, FNCN, 14, 507 (2006).

3. W.J. Rodgers, P.W. May, N.L. Allan, J.N. Harvey, J. Chem. Phys., 142, 214707 (2015).

4. P.W. May, J.N. Harvey, N.L. Allan, J.C. Richley, Y.A. Mankelevich, J. Appl. Phys., 108, 014905 (2010).

5. P.W. May, J.N. Harvey, N.L. Allan, J.C. Richley, Y.A. Mankelevich, J. Appl. Phys., 108, 114909 (2010).

6. A.A. Emel'yanov, A.K. Rebrov, I.B. Yudin, Tech. Phys., 61, 1821 (2016).

7. A. Cheesman, J.N. Harvey, M.N. Ashfold, J. Phys. Chem. A 112, 11436 (2008).

8. M.Yu. Plotnikov, E.V. Shkarupa, J. Appl. Mech. Tech. Phys. 58, 402 (2017).

9. A.K. Rebrov, A.A. Emel'yanov, M.Yu. Plotnikov, I.B. Yudin, J. Appl. Mech. Tech. Phys. 58, 881 (2017).

10. A. Rebrov, M. Plotnikov, Yu. Mankelevich, I. Yudin, Phys. Fluids, 30, 016106 (2018).

11. J.-L. Guizot, K. Nomoto, A. Matsuda, Surf. Sci. 244, 22 (1991).

12. A.A. Emel'yanov, A.K. Rebrov, I.B. Yudin, Tech. Phys. 61, 1821 (2016). 